\title{
Johannes Helmrath, Wege des Humanismus
}

\section{Aude-Marie Certin}

\section{OpenEdition \\ Journals}

Édition électronique

URL : http://journals.openedition.org/ifha/8735

DOI : $10.4000 /$ ifha. 8735

ISSN : 2198-8943

Éditeur

IFRA - Institut franco-allemand (sciences historiques et sociales)

\section{Référence électronique}

Aude-Marie Certin, "Johannes Helmrath, Wege des Humanismus », Revue de l'IFHA [En ligne], Date de recension, mis en ligne le 02 novembre 2017, consulté le 23 septembre 2020. URL : http:// journals.openedition.org/ifha/8735; DOI : https://doi.org/10.4000/ifha.8735

Ce document a été généré automatiquement le 23 septembre 2020.

(C)IFHA 


\title{
Johannes Helmrath, Wege des
}

\section{Humanismus}

\author{
Aude-Marie Certin
}

\section{RÉFÉRENCE}

Johannes Helmrath, Wege des Humanismus, Tübingen: Mohr Siebeck (Spätmittelalter, Humanismus, Reformation, 72), 2013, 449 p., $119 €$

2013 
Dans ce recueil d'articles, Johannes Helmrath a réuni dix textes publiés entre 2000 et 2009 sur le thème de l'humanisme européen. Le premier d'entre eux propose une forme d'essai sur l'humanisme en Allemagne. L'auteur y décrit de façon très éclairante les spécificités de ce mouvement dans les différents espaces germaniques où il s'est déployé (les cours, les villes, les universités, les cloîtres) avant de proposer quelques réflexions conclusives sur le lien entre l'humanisme tardif et la Réforme. Les trois articles suivants portent sur la diffusion de l'humanisme en Europe de façon plus générale. J. Helmrath s'intéresse à la fois aux acteurs qui ont joué un rôle important en ce domaine (en particulier à Enea Silvio Piccolomini) et aux mediums de cette diffusion culturelle (comme la circulation des manuscrits). Un autre texte souligne l'importance des conciles de Constance (1414-1418) et de Bâle (1431-1449) dans ces transferts culturels, notamment à travers le rôle de marché du livre et d'espace d'échanges qu'ils purent jouer. Trois autres articles envisagent différents domaines où les humanistes ont réélaboré de façon riche et créative l'héritage antique, en particulier l'art oratoire et l'écriture de l'histoire. Deux autres textes de l'auteur évoquent des humanistes qui se sont illustrés dans les conflits ou les polémiques auxquels ils ont pris part, tel Poggio Bracciolini. Enfin, le dernier article de ce recueil porte sur la numismatique et s'intéresse aux formes de reprise des motifs présents sur les pièces antiques à la Renaissance.

Ce livre a pour grand intérêt de proposer une approche renouvelée et actualisée de nombreuses questions traitées de longue date en histoire sur le thème de l'humanisme, depuis J. Burckhardt entre autres. Ainsi J. Helmrath revient-il sur le contexte social et culturel de l'émergence de l'humanisme, sur le rôle de la «bourgeoisie » dans celle-ci ou sur la question de la «nation» dans l'humanisme allemand. En outre, cet ouvrage offre une précieuse synthèse non seulement sur l'humanisme allemand, mais aussi sur les aléas de l'historiographie allemande portant sur cette question aux $\mathrm{XIX}^{\mathrm{e}}$ et $\mathrm{XX}^{\mathrm{e}}$ siècles, en particulier avant et après 1945. 
INDEX

Thèmes : Histoire de la culture, Histoire de l'art, Histoire des idées, Historiographie/ méthodologie

Index chronologique : Période moderne 